\title{
A imputabilidade moral na Crítica da Razão Pura
}

\author{
Aguinaldo Pavão*
}

Resumo: Este artigo analisa o tratamento dado por Kant na Primeira Critica à imputabilidade moral, concentrando-se basicamente na III parte do capítulo II do livro segundo da Dialética Transcendental, denominado "Solução das idéias cosmológicas da totalidade da divisão dos eventos a partir das suas causas". Nesta parte da Crítica da razão pura, Kant apresenta, dentro de sua estratégia argumentativa que visa resolver o problema da terceira antinomia, a distinção entre caráter empírico e caráter inteligível. A partir da dupla maneira de consideração do sujeito agente, procura-se entender a tese de Kant sobre a imputabilidade moral. É questionada a posição de Kant defendida em B 583 de que um juízo de imputação requer o desprezo pelas condições empíricas, sejam estas internas ou externas.

Palavras-chave: caráter inteligível - liberdade - responsabilidade - causalidade da razão

$\mathrm{Na}$ III parte do capítulo II do livro segundo da Dialética transcendental, denominado "Solução das idéias cosmológicas da totalidade da divisão dos eventos a partir das suas causas", Kant expõe a distinção entre caráter empírico e caráter inteligível e atribui ambos ao mesmo sujeito agente. Kant argumenta que, para um sujeito dotado de uma causalidade livre, tem de se atribuir um "caráter inteligível", que é o caráter de uma causalidade por liberdade 1 , visto que os efeitos (ações) deste sujeito, conquanto repercutam no mundo dos sentidos, possuem causas que independem de qualquer condição empírica. Contudo, este mesmo sujeito, como membro do mundo dos sentidos, possui um cará-

* Professor de Filosofia UEL (PR), mestre em Filosofia pela UFRGS e doutorando em Filosofia na UNICAMP. 
ter empírico e suas ações têm de ser consideradas na interconexão necessária dos fenômenos conforme a causalidade natural.

Mas este argumento parece ser um tanto obscuro e realça as dificuldades da resolução da terceira antinomia. Como é possível a atribuição ao mesmo sujeito de um duplo caráter? Como compreender que uma mesma ação, como fenômeno, seja tanto o resultado de determinações causais naturais como o efeito de uma causalidade inteligível, independente de qualquer condição temporal?

Com relação a estas questões, a resposta kantiana parece se dirigir para uma necessária dupla consideração do sujeito agente, na medida em que o ser humano é compreendido como algo radicalmente distinto do resto da natureza. Diz Kant:

Exclusivamente o homem que de outra maneira conhece toda a natureza somente através dos sentidos, se conhece a si mesmo mediante uma pura apercepção [...] para si mesmo, ele certamente é, de uma parte fenômeno, mas de outra, ou seja no que se refere a certas faculdades um objeto puramente inteligível porque a sua ação de modo algum pode ser computada na receptividade da sensibilidade. Denominamos estas faculdades de entendimento e razão (CRPu, B 574-575)2.

Ora, o idealismo transcendental, conforme assinala corretamente Henry E. Allison, considera o espaço, tempo e as categorias do entendimento como condições epistêmicas e não ontológicas, abrindo-se, assim, um 'conceptual space' para o pensamento de objetos não empíricos, dentre os quais estão os agentes humanos como agentes racionais, que podem ser considerados como coisas em si mesmas (cf. Allison 2, p.44). Dessa forma, os seres humanos podem atribuir-se a si mesmos um caráter inteligível, já que as condições epistêmicas mencionadas não representam a propriedade de todas as coisas em geral.

Pode-se dizer que Kant pretende com a dupla maneira de consideração do sujeito agente destacar que o determinismo causal natural é o ponto de vista legítimo e necessário para a explicação das ações humanas, dada a condição destas de eventos empíricos e de produtos de seres sensíveis como são os seres humanos. Todos os eventos empíricos caem dentro das condições espaço-temporais e categoriais, unicamente mediante as quais nós podemos conhecê-los. Ora, sendo as ações huma- 
nas eventos empíricos, é forçoso que as consideremos dentro dos quadros epistêmicos apresentados por Kant na "Estética" e na "Analítica".

Se o determinismo causal natural é o ponto de vista legítimo e necessário para a explicação de todos os eventos empíricos, nos quais se incluem as ações humanas, parece não haver razões para que tal ponto de vista impeça compreensões alternativas caso estas não levantem as mesmas pretensões que aquela assegura para si com exclusividade. Ora, as ações humanas, dada a singularidade dos seres humanos, seres dotados de razão e entendimento (sobretudo de razão), requerem um outro ponto de vista possível, o qual seja capaz de justificá-las praticamente ${ }^{3}$. Assim, faz-se necessário considerar o caráter empírico do sujeito agente como uma sinalização sensível, através das ações, de seu caráter inteligível como causas destes enquanto fenômenos ( $\mathrm{CRPu}, \mathrm{B}$ 567 e B 574).

Todavia, uma questão aqui parece se impor. Dada a "natureza" numênica da liberdade e supondo, como é razoável supor, que nem todas as ações são livres, como podemos nos certificar que determinadas ações, isto é, certos eventos empíricos, expressem a presença ou a ausência da liberdade? Trata-se de saber como podemos imputar moralmente - ato que pressupõe a atribuição de liberdade ao agente - se o caráter inteligível do ser humano, unicamente mediante o qual nós podemos considerá-lo livre, nos é inacessível? Diz Kant:

[...] a moralidade própria das ações (mérito e culpa), mesmo a de nosso próprio comportamento, permanece-nos totalmente oculta. As nossas responsabilidades só podem ser referidas ao caráter empírico. Mas quanto disto se deve imputar ao efeito puro da liberdade, quanto à simples natureza e quanto ao defeito de temperamento do qual não se é culpado, ou à natureza feliz (merito fortunae) do mesmo, eis algo que ninguém pode perscrutar e conseqüentemente, também não julgar (richten) com toda a justiça (CRPu, B 579, nota).

Dessa citação interessa-me reter dois pontos. Um conduz novamente à questão sobre a responsabilidade de nossas ações, pois, uma vez que não sabemos se as ações são efeito da liberdade ou da natureza, convém entender como é possível ainda falar em imputabilidade moral. $\mathrm{O}$ segundo ponto consiste na necessidade de compreender o que Kant 
quer significar com a frase "As nossas responsabilidades só podem ser referidas ao caráter empírico". Tomo inicialmente a segunda questão.

Parece-me que o que Kant quer dizer com a frase acima é que as responsabilizações que fazemos partem do caráter empírico do agente pois nesta esfera é que nos deparamos com ações, "sinais sensíveis", que julgamos dignas de louvor ou de censura -, mas são referidas (atribuídas) ao caráter inteligível, uma vez que é em referência a esta "lei da causalidade" que estamos autorizados a imputar. Na discussão do exemplo da mentira maldosa (que veremos na seqüência), a atribuição de responsabilidade será dirigida ao caráter inteligível do homem. Diz Kant: "A ação é atribuída ao caráter inteligível do homem e agora, no momento em que mente, ele é totalmente culpado" (die Handlung wird seinem inteligibeln Charakter beigemesen, er hat jetzt, in dem Augenblicke, da er lügt, gänzlich Schuld) (CRPu, B 583). Atentando para o verbo dessa frase (beimessen - atribuir, imputar) e contrastando-o com o usado na outra frase ("Unsere Zurechnungen können nur auf den empirischen Charakter bezogen werden"; grifo nosso) - pode-se dizer que a afirmação "As nossas responsabilidades, ainda que só possam ser referidas ao caráter empírico, têm de ser, contudo, atribuidas/imputadas ao caráter inteligível" expressaria corretamente a relação que caráter empírico e inteligível mantém com os juízos de imputabilidade. Assim, embora aparentemente possa ser considerada ambígua a frase "As nossas responsabilidades só podem ser referidas ao caráter empírico" - seria ambígua porque a frase "as nossas responsabilidades só podem ser atribuidas ao caráter empírico", devido à proximidade semântica de 'referir' e 'atribuir', pode ser considerada sinônimo daquela, ou ainda a frase "as nossas responsabilidades só podem ser referidas ao caráter inteligível" pode ser válida desde que ponderado o sentido de 'referir' ela se mantém coerentemente ao lado da atribuição das ações ao caráter inteligível.

$\mathrm{Na}$ linha dessas reflexões, alguém poderia interpretar Kant como o fez Schopenhauer, dizendo que "a responsabilidade moral do homem refere-se, em primeiro lugar e ostensivamente, àquilo que ele faz, mas no fundamento, àquilo que ele é" (Schopenhauer 23, p. 92). Ora, aquilo que o homem faz, sendo para nós acessível pela experiência, é expressão do seu caráter empírico. Assim, o operari humano, sujeito à lei da natureza, é o alvo inicialmente visado por nossos juízos de imputabilidade 
- poder-se-ia dizer que é nesse sentido que "as nossas responsabilidades só podem ser referidas ao caráter empírico". Porém, de acordo com a leitura de Schopenhauer, a incidência precisa de um juízo de imputabilidade deve recair sobre o que o homem é, ou seja, sobre o que o homem pode ser de acordo com a sua essência. Ora, se o caráter inteligível, "presente [...] em todos os atos do indivíduo e impresso em todos eles, como o carimbo em mil selos [...] determina o caráter empírico deste fenômeno [as ações exteriorizadas pela lei da causalidade - AP] que se manifesta no tempo e na sucessão dos atos" (Cf. Schopenhauer 23 , p. 91$)^{4}$, então deve ser a ele propriamente imputada a ação humana. Assim, Schopenhauer poderia compatibilizar facilmente as duas frases de Kant acima tematizadas, afirmando: “as nossas responsabilidades só podem ser referidas ao operari mas têm de ser atribuídas ao esse".

A questão está em que, para Schopenhauer, a conclusão que se segue a partir disso é que a liberdade não pode mais ser entendida como um poder que o agente possui de agir de outro modo. $\mathrm{O}$ meu agir é determinado necessariamente, seja do ponto de vista exterior por motivos (isto é, uma espécie de causalidade empírica), seja do ponto de vista interno pelo caráter inteligível. Como a liberdade só pertence ao caráter inteligível, e o caráter inteligível apenas diz respeito ao 'esse' e não ao 'operari', ela só pode ser entendida como um poder de ser de outro modo, ou melhor, um poder que homem possui de ter sido outro ${ }^{5}$.

Ora, essa limitação da liberdade a uma escolha, mediante um ato inteligível, do nosso ser parece chocar-se com o pensamento de Kant. De fato, Kant afirma que a "ação (Handlung) é atribuída ao caráter inteligível do homem" e, na seqüência, parece tornar-se mais difícil a compatibilização com Schopenhauer quando lemos: "e agora, no momento em que mente, ele é totalmente culpado; portanto, desconsiderando todas as condições empíricas do ato, a razão era integralmente livre, e a mentira é de todo imputável a sua omissão" (CRPu, B 583). Para o meu interesse nessa discussão, importa sublinhar nessa passagem a parte "no momento em que ele mente" e "a razão era inteiramente livre". Parece ser clara a sugestão de Kant de que a ação particular (no exemplo, a mentira maldosa) resultou de uma razão que era livre para mentir ou não mentir6.

No parágrafo seguinte ao da citação acima, Kant argumenta que a razão, embora estando presente e sendo "sempre a mesma em todas as 
ações do homem em todas as circunstâncias temporais", não é, contudo, "no tempo nem atinge um novo estado no qual não estava", uma vez que, em relação a este novo estado, "ela é determinante, mas não determinável". Assim sendo, não cabe perguntar por que a razão não se determinou de outro modo. Poder-se-ia indagar por que a razão "mediante a sua causalidade [...] não determinou diversamente os fenômenos". Porém, em relação a isto, "qualquer resposta é impossível. Com efeito, um outro caráter inteligível teria dado um outro caráter empírico" (CRPu, B 584). Se esta última frase de Kant é isolada, pode-se tomá-la como significando que se um homem que mente maldosamente tivesse um outro caráter moral, isto é, tivesse um outro "sinal distintivo [...] enquanto ser racional dotado de liberdade" (Kant 21, p. 135) ${ }^{8}$ que comportasse princípios práticos proibitivos do mentir, teria então um caráter empírico, isto é, um comportamento diverso, sempre dizendo a verdade. Embora isso até possa ser considerado verdadeiro, o que Kant quer dizer é que um outro caráter inteligível daria um outro caráter empírico porque de uma outra lei da causalidade não-empírica resultaria, como efeito, um outro fenômeno. Schopenhauer interpreta a frase em pauta no primeiro sentido com o agravante de compreender o caráter inteligível como caráter moral imutável (no sentido antropológico; cf. Schopenhauer 23, p. 89) 9

Ora, o contraste entre caráter inteligível e empírico na Crítica da razão pura não tem sentido psicológico ou antropológico (cf. Allison 1, p. 484-5) ${ }^{10}$, mas sim a função de distinguir os modos de operar da causalidade, na medida em que esta pode ser duplamente considerada como causalidade empírica e inteligível.

No entanto, Schopenhauer poderia resistir a essa leitura. A base textual mais forte contra a sua tese parece estar em outro lugar, a saber, na seguinte advertência de Kant:

Mas porque o caráter inteligível resulta nas circunstâncias existentes, exatamente nestes fenômenos e neste caráter empírico é uma questão que ultrapassa tão de longe a faculdade de nossa razão para responder, e até todo o direito de ela sequer perguntar, como se se indagasse porque o objeto transcendental de nossa intuição sensível externa só dá uma intuição no espaço e não em qualquer outro tipo de intuição (CRPu, B 585). 
Assim, quando se quer defender a tese de que o caráter inteligível, entendido como o 'esse' do homem, se está tentando sustentar, senão exatamente o porquê de o caráter inteligível resultar num determinado caráter empírico (teria de se responder porque o homem é o que é), algo que ultrapassa os limites legítimos do poder de nossa razão para responder. Afirmar que Kant, com a distinção entre caráter empírico e inteligível, nos retirou "do erro fundamental que deslocava a necessidade para o 'esse' e a liberdade para o 'operari"' (Schopenhauer 23, p. 92) e nos fez perceber que a relação é inversa, isto é, 'operari sequitur esse', é supor-se autorizado a perscrutar o imperscrutável. Na verdade, Kant, ao distinguir caráter empírico do caráter inteligível, nos retirou do seguinte erro fundamental: considerar o operari como o faz Schopenhauer, ou seja, como suscetível de uma única leitura, não sendo possível de ser considerado senão sob o ponto de vista da causalidade natural.

Deve-se notar, ainda, que o não ter direito de indagar sobre por que o caráter inteligível resulta num determinado caráter empírico está vinculado à não autorização de perguntar sobre de onde surge a ação livre e quando ela é iniciada. De fato, visto que condições espaço-temporais só podem ser referidas ao caráter empírico, a causalidade livre da razão "em seu caráter inteligível não surge, nem começa por volta de um certo tempo a fim de produzir um efeito. Pois, do contrário ela mesma ficaria submetida a lei natural dos fenômenos" (CRPu, B 579-580) ${ }^{11}$.

Voltemos a questão sobre a responsabilidade de nossas ações. Somente pode haver imputabilidade (Zurechnungskeit) onde há liberdade. Ora, se não há condições de saber (kennen) da existência ou não da liberdade, não se cairia talvez na seguinte situação: ou nós abdicamos qualquer juízo de imputabilidade ou expomo-nos ao risco da injustiça nos julgamentos que fazemos? Pareceria que o não poder "julgar com toda a justiça" neste caso significaria não poder julgar com nenhuma justiça, visto que sugeriria um julgamento cego? Nesta perspectiva, diz Jonathan Bennett, comentando a citação de Kant em pauta:

Dizer que não se pode 'julgar com plena justiça' é pouco. De fato, não temos a menor base para crer que qualquer juízo de imputabilidade tenha a mínima justiça ... Visando apoiar a noção ordinária de responsabilidade moral, a teoria de Kant a aniquila (Bennett 5, p. 223). 
Convém, tendo presente tais questionamentos e leituras, retornar à Crítica da razão pura na busca de uma possível resposta de Kant, seja explícita ou não, ao problema levantado. Examinando bem a nota da $C R P u$, B 579, talvez se consiga dissipar um pouco as dificuldades levantadas. Na verdade, Kant não diz que nós não sabemos se as ações são efeitos da liberdade ou da natureza. Kant afirma que nós não sabemos o quanto deve ser imputado à liberdade ou à natureza ${ }^{12}$. Desse modo, seria possível uma interpretação favorável a Kant. De fato, a afirmação de Kant não impede totalmente o juízo moral, ela apenas restringe a sua acribia. Neste sentido, pode-se admitir que ninguém julga com toda a justiça, o que não significa eliminar todo o julgamento. A tese simplesmente introduziria cláusulas de reservas quanto ao seu caráter peremptório.

Todavia, para se conceder validade à compreensão de Kant sobre a imputabilidade moral na $C R P u$ deve-se cuidar ainda de um outro ponto. Refiro-me ao exemplo, apresentado por Kant, da mentira maldosa, causadora de uma certa confusão para a sociedade. Em primeiro lugar, segundo Kant, esta ação deve ser examinada "quanto às motivações a partir das quais emergiu" para em seguida a julgarmos "como ela pode ser imputada ao agente juntamente com as suas conseqüências" ( $\mathrm{CRPu}$, B 582). A primeira questão diz respeito ao caráter empírico da ação, exigindo que compreendamos a mentira maldosa dentro de uma série de causas que a determinam naturalmente. Assim, encontramos como fatores determinantes uma "educação defeituosa, [...] más companhias, $[. .$.$] índole insensível à vergonha, [. .$.$] leviandade, [. .$.$] irreflexão", bem$ como "causas ocasionais que a tal ato deram azo" (CRPu, B 582). Tais fatores, que expressam tanto traços de caráter (sentido antropológico) quanto determinações do ambiente, apenas explicam como a ação ocorreu, não permitindo, portanto, julgá-la moralmente. Ora, a imputação é garantida pelo segundo procedimento de exame. Neste procedimento, "apesar de se crer que a ação esteja determinada mediante tal [série de causas que determinam um efeito natural dado - AP], nem por isso admoesta-se menos o agente" (CRPu, B 582-583). Mas como podemos justificar uma censura a um agente se consideramos que sua ação resulta de uma causalidade natural? Conforme Kant esta censura está baseada numa "lei da razão por meio da qual se encara esta última como uma causa que, sem levar em conta todas as condições empíricas menciona- 
das, poderia e deveria determinar diversamente o comportamento do homem" (CRPu, B 583). Para Kant, ainda que adversidades empíricas se coloquem, a causalidade da razão é completa. Nesse sentido, entende-se a afirmação já referida segundo a qual "a ação é atribuída ao caráter inteligível do homem, e agora, no momento em que mente, ele é totalmente culpado" (id.).

Assim sendo, a culpabilidade de um homem que mente maldosamente requer um desprezo pelas condições empiricas, sejam estas internas ou externas. Kant diz ainda, no mesmo parágrafo, que nós temos de considerar tal ato, na perspectiva de censura do agente, de um lado, como se a série decorrida das condições não tivesse ocorrido ${ }^{13} \mathrm{e}$, de outro lado, como se se tratasse de início espontâneo, por parte do agente, de uma série de conseqüências. Parece um tanto difícil aceitar que, quando se propõe a avaliar a culpabilidade ou não de um ser humano, seja necessário desconsiderar condições empíricas passadas. Se uma pessoa teve uma educação defeituosa, más companhias e cometeu uma ação censurável por leviandade, parece que, nestes casos, seria plausível a possibilidade de que esta pessoa determinasse, mediante a causalidade de sua razão, um comportamento diverso do praticado. Mas, em sendo assim, seria preciso sustentar que tais condições não são relevantes, na medida em que não determinam necessariamente a ação. Tal irrelevância das condições deve resultar da avaliação que se faz das mesmas, não de uma desconsideração prévia por qualquer condição empírica. Considere-se o caso, mencionado por Kant, de que se verifique no agente, conjugadamente a outros fatores, a "malignidade de uma índole insensível à vergonha". Neste caso, se estaria diante de um grave distúrbio de personalidade, o que tornaria insustentável qualquer expectativa de comportamento moral do agente. Uma pessoa "insensível à vergonha" revela uma falha estrutural na formação de sua consciência moral, apresentando-se como moralmente incivilizada. Nesse contexto, parece intervir uma condição empírica relevante. Assim, o agente não estaria sujeito à imputabilidade, uma vez que a causalidade determinante não foi a da razão (livre e de modo algum afetada pela sensibilidade), mas a causalidade natural que subtrai todo argumento de responsabilização moral. Dessa forma, a argumentação de Kant em torno do exemplo da mentira maldosa se revela também problemática, sobretudo em função de ele sugerir que todas as ações humanas seriam livres ${ }^{14}$. 
A pretensão de Kant é mostrar que liberdade e necessidade natural podem, numa mesma ação, "ocorrer independentemente uma da outra e sem interferências recíprocas" (CRPu, B 585). Logo, o argumento principal em favor desta tese é, de fato, a distinção entre fenômeno e númeno com a conseqüente abertura do já referido espaço conceitual que nos permite pensar a possibilidade das ações humanas fora das condições epistêmicas (espaço-temporais e categoriais). Todavia, o recurso a este espaço conceitual, onde se justifica a compreensão das ações humanas como resultado de uma causalidade por liberdade, isto é, numênica, deve ser validado apenas "onde há alguma razão para ir além da causalidade fenomênica, e estas são encontradas apenas na volição humana" (Beck 4, p. 189). Com efeito, na natureza inanimada ou meramente animal não existem razões para o recurso a uma compreensão diferente da que nos é oferecida pelo determinismo natural (cf. CRPu, B 574). Ora, se o recurso a uma causalidade numênica somente se justifica onde existe alguma razão para irmos além da causalidade fenomênica, e mesmo que este apelo à causalidade numênica só seja justificado quando se tratar de volições humanas, poder-se-ia considerar que, nas ações humanas, tendo em vista a avaliação de responsabilidade das mesmas, o apelo à causalidade numênica pode ser impugnado na medida em que inexistam razões para se ir além da causalidade fenomênica. Tome-se novamente o exemplo da mentira maldosa. É razoável supor que um tal ato resulte de certas condições empíricas que afetem completamente (necessitariamente) a volição humana (consideremos, mais uma vez, o fator da "malignidade de uma índole insensível à vergonha" no sentido mais forte). Assim, em casos semelhantes a este, não existiria razão para irmos além da causalidade fenomênica. Convém que se atente que o que está em questão aqui não é em primeiro lugar a precisão dos exemplos, mas sim a de perceber que a liberdade não está sempre presente nas ações humanas, não se justificando, portanto, um desprezo a priori das condições empíricas do agente quando visamos juízos de imputabilidade. $O$ que se questiona em Kant é a tese de que, independentemente de qualquer afeto, a razão é moralmente soberana (e não que ela deva ser moralmente soberana). Ora, um sujeito com a lack of moral sense (ao qual faltaria o sentimento de vergonha), seria um caso empírico de uma patologia ${ }^{15}$ diante da qual a razão não teria soberania. 
Nesse sentido, pode-se buscar um aval no próprio Kant. Com efeito, ele considera que a primeira infância e a loucura, incluindo nesta última estados psicológicos como uma melancolia extrema ou depressão, representam condições empíricas que nos levam a considerar um agente como não livre ${ }^{16}$. A discriminação de atos livres de atos não livres se deixa perceber também no texto Resposta à pergunta: que éo iluminismo? onde Kant fala da "menoridade" de que o próprio homem é culpado, a qual se distingue da menoridade que reside na falta de entendimento ou que se baseia no fato da natureza não nos ter ainda "libertado do controle alheio" (Kant 10, p. 11). A menoridade imputável é a menoridade a qual o Iluminismo (Aufklärung) empenha-se na crítica, responsabilizando o homem que não saiu deste estado precisamente em função de que o mesmo poderia não mais continuar menor, ou seja, responsabiliza-se uma menoridade que resulta da liberdade. Contrastativamente a esse caso de menoridade imputável temos uma menoridade não imputável, isto é, atos de menoridade não livres, empiricamente destacados, e, assim, insuscetíveis de responsabilização. Ainda, na Crítica da faculdade do juizo, vemos Kant, ao distinguir afetos (Affekten) de paixões (Leidenschaften) ${ }^{17}$, sinalizar a possibilidade de um impedimento empírico da liberdade ${ }^{18}$, ao afirmar que as paixões "são inclinações que dificultam ou tornam impossível toda determinabilidade do arbítrio por princípios". Logo, as paixões podem limitar e inclusive suprimir a liberdade ${ }^{19}$.

Assim sendo, pode-se retornar com outros olhos à afirmação de Kant segundo a qual a ação do homem "de modo algum pode ser computada na receptividade da sensibilidade" (CRPu, B 575). Ao que parece, certas ações podem ser computadas na receptividade da sensibilidade, demarcando-se assim alguma fronteira entre o imputável e o não imputável, entre as ações livres e as não livres. 
Abstract: This article analyzes the treatment given for Kant in the First Critical to the moral imputability, concentrating basically in III part of chapter II of the book second of the Transcendental Dialectic, called "Solution of the cosmological ideas of the totality of the division of the events from its causes". In this part of the Critique of Pure Reason, Kant presents, inside of its argumentativa strategy that aims to decide the problem of the third antinomy, the distinction between empirical character and intelligible character. From the double way of consideration it subject agent, search the thesis of Kant on the moral imputability. The position of Kant defended in B 583 of that an imputation judgment requires the disdain for the empirical conditions, as much interns as external, is questioned.

Key-Words: intelligible character - freedom - responsibility - causalidade of the reason

\section{Notas}

1. A liberdade, como causa eficiente, tem um caráter. E caráter, conforme Kant define, é uma lei da causalidade da causa eficiente. (Cf. Kant 8, p. 274, B 567; Kant 9-Doravante CRPu). Sobre a variação do significado de "caráter" (Charakter) em Kant, veja nota 8 .

2. Ver também em Kant 12, III seção, p. 153, § 13 / BA 108; Tugendlehre, $\S 3$, Kant 19, p. 276, Ak 418; Kant 20.

3. Kant, $C R P u$, B 577-578: "Todas as ações do homem no fenômeno estão determinadas segundo a ordem da natureza, por seu caráter empírico... Mas se ponderarmos justamente estas mesmas ações com relação à razão, e não à especulativa a fim de explicar aquelas segundo a sua origem, mas exclusivamente na medida em que a razão é a causa de sua produção, numa palavra, se compararmos estas ações com a razão tendo em vista um propósito prático, então encontraremos uma regra ou uma ordem que são totalmente diversas da ordem da natureza" (grifos do autor).

4. Sobre a "interpretação" de Schopenhauer acerca da distinção kantiana entre caráter inteligível e caráter empírico, veja também Schopenhauer 22, II, $\S 20$, p. 142; id., § 28, p. 203-7; id. IV, § 55, p. 379-85; Schopenhauer 24, p. 117 s, p. 191-5. 
5. Schopenhauer 23, p. 91: "tudo o que [o homem] faz acontece necessariamente. Mas no seu 'esse', aí está a liberdade. Ele poderia ter sido outro: e naquilo que ele é estão culpa e mérito".

6. Na Crítica da Razão Prática Kant afirma que "satisfazer ao mandamento categórico da moralidade está em poder de cada um em todo tempo" (A 64). A tradução de Artur Morão (Kant 13,p. 49) opta por " está sempre em poder de cada um" para "ist in jedes Gewalt zu aller Zeit". A meu ver o tradutor português não é feliz em sua opção, pois ele vela uma dificuldade filosófica no pensamento de Kant, a saber, a dificuldade de relacionar a ação moral e tempo. Veja também a esse respeito o destaque dado por Victor Delbos à expressão "zu aller Zeit" (Delbos 6, p. 366 , nota 2 ).

7. Veja nota anterior.

8. É digno de registro a mudança de sentido que o termo "caráter" (Charakter) sofre no pensamento de Kant. Se na Crítica da razão pura, como vemos, caráter é a "lei da causalidade", na Fundamentação da metafisica dos costumes, embora sem definição clara, o termo já é tomado em outro sentido (por exemplo; seção I, $\S \S 1$ e 11 , onde Kant o contrasta com o temperamento, sugerindo, no $\S 1$, que caráter seria o modo como a vontade usa os talentos do espírito, as qualidades do temperamento e os dons da fortuna). Na Antropologia de um ponto de vista pragmático, o caráter é a "propriedade da vontade pela qual o próprio sujeito se liga a princípios práticos determinados que são indefectivamente prescritos por si mesmo através de sua própria razão" (Kant 21, p. 139-140). Segundo Henry E. Allison, a ênfase no sentido antropológico de caráter, que ao seu ver surge implicitamente a partir da segunda Crítica, marca uma mudança que deve ser entendida como "concomitantes às mudanças na teoria moral de Kant produzidas pela introdução do princípio da autonomia" (Allison 2, p. 140).

9. Segundo o ponto de vista de Victor Delbos, Schopenhauer retém o substancialismo "plus ou moins explicite" da teoria kantiana do caráter inteligível (cf. Delbos 6, p. 365-7). Este substancialismo se verificaria na consideração de que a ação resultaria de uma "determination essencialle de la chose en soi comme chose" (id. p. 367). Para Delbos, Kant se inclinaria, na Crítica da Razão Prática a eliminar este pendor substancialista, tomando como origem do caráter uma ação intemporal em sua relação direta com a lei moral" (ibid., id.).

10. Allison assinala, corretamente, que Kant também aplica a distinção entre caráter empírico e inteligível ao agente causal, isto é, o sujeito da causalidade, porém, segundo ele, "não há indicação, ao menos na exposição inicial, de que este sujeito se deva conceber em termos psicológicos, i.e., como pessoa" (Allison 1, p. 485). Não obstante, Kant, ao afirmar que é pelo caráter empírico "que podemos considerar o homem quando simplesmente o observamos e quando, tal qual ocorre na 
Antropologia, pretendemos investigar fisiologicamente as causas de suas ações" $(\mathrm{CRPu}, 279, \mathrm{~B} 578)$ parece sugerir uma aproximação de sentido entre a lei da causalidade empírica e caráter antropologicamente considerado.

11. Na Religião, Kant apresenta uma distinção que tem uma incidência esclarecedora neste ponto. Trata-se da distinção do conceito de "Origem primeira" Ursprung (der erste), que significa "a derivação de um efeito da sua primeira causa, i.e, daquela que, por seu turno, não é efeito de outra causa da mesma espécie (Kant 17, p. 45). Esta pode se distinguir em "origem racional" $\mathrm{e}$ "origem temporal". A "origem racional" toma "em conta apenas a existência do efeito", já a "origem temporal" "o acontecer do mesmo, por conseguinte, o efeito como ocorrência é referido a uma a uma causa no tempo. Se o efeito é referido a uma causa que a ele está ligada segundo leis da liberdade [...] então a determinação do arbítrio à sua produção é pensada [...] como ligada [...] somente na representação da razão, e não pode ser derivada de qualquer estado precedente" (id., id.; Kant 18). Portanto, a pergunta pela "origem temporal das ações livres como tais (como se fossem efeitos da natureza) é, pois, uma contradição" (Kant 17, p. 45-6).

12. No original: "Wie viel aber davon reine Wirkung der Freiheit, wie viel der blossen Natur" (grifo nosso).

13. Para Allison, a pretensão de Kant seria a de que "a disponibilidade de uma explicação empírica-causal de uma ação por si mesma não exlcui a possibilidade de supor que o agente poderia ter agido de outro modo e portanto de sustentar que o agente é responsável" (Allison 2, p. 42).

14. Esta questão é assinalada por Jonathan Bennett (Bennett 5, p. 233) e Lewis White Beck que, embora numa perspectiva de argumentação diferente da de Bennett, afirma: "Todos os fenômenos têm duas dimensões de relações, uma para o fenômeno anterior, uma para o númeno. A segunda dimensão ou relação não é o que se quer significar por liberdade num sentido interessante, porque ela é indiscriminadamente universal. Liberdade como um predicado universal é destituída de interesse" (Beck 4, p. 188). Embora Beck não esteja se referindo à universalidade indiscriminada quanto às ações humanas (o que faz Bennett), a sua ponderação a meu ver pode valer também nesse sentido, uma vez que o conceito de liberdade como predicado de toda e qualquer ação humana, ao desconsiderar a possibilidade do arbítrio humano ser necessitado patologicamente, apresenta-se com interesse reduzido, dada a sua miopia quanto às ocorrências patológicas suscetíveis ao agir humano.

15. Bem entendido, patologia no sentido moderno (e não kantiano) do termo.

16. Cf. Kant. Metaphisik L., edição da Academia, v. 28, p. 254-7, citado em Allison 2, p. $59,74$. 
17. Diz Kant: “Afetos são especificamente distintos de paixões. Aqueles referemse meramente ao sentimento; estas pertencem à faculdade de apetição e são inclinações que dificultam ou tornam impossível toda determinabilidade do arbítrio (Willkür) por princípios. Aqueles são impetuosos e impremeditados; estas, duradoras e refletidas" (Kant 15, p. 118, B 121, nota 128). O exemplo fornecido por Kant nesta nota é o da indignação (Unwille) que, sendo um afeto, é cólera (Zorn) e, sendo paixão, é ódio (Hass), sede de vingança. Na Tugendlehre Kant também apresenta esta distinção. O exemplo é o mesmo. A cólera ou ira, como sentimento repentino e brusco, é uma propensão a um afeto. $\mathrm{O}$ ódio - inclinação permanente - é uma paixão. A diferença está nas definições. Os afectos "pertencem ao sentimento, na medida em que este, precedendo à reflexão (Überlegung), a impossibilita ou a dificulta" (Kant 19, p. 265, Ak 407). A paixão "é o apetite sensível convertido em inclinação permanente" (id., Ak 408). Assim, temos ao lado da já conhecida vítima da paixão (o arbítrio), a vítima do afeto (a reflexão, ou raciocínio). A questão que se coloca, num caso extremo, é até que ponto pode arbítrio se determinar livremente considerando-se a impossibilidade da reflexão? Por certo, isso dificulta somente o que é uma tese mais moderada de Kant.

18. Referência no mesmo sentido à Crítica da faculdade do juizo é feita por Allison 2 , p. 260, n. 12.

19. Também nas Lecciones de ética (De Imputatione): "Podemos atribuir algo a uma pessoa sem chegar a imputar-lhe; por exemplo, podemos atribuir suas ações a um louco ou a um ébrio, mas não imputar-lhes. $\mathrm{Na}$ imputação, a ação tem de ter sua origem na liberdade. Certamente, não se podem imputar suas ações ao ébrio, senão à própria embriaguez" (Kant 11, p. 97, cf. também p. 101). A referência ao ébrio lembra Aristóteles: "O homem embriagado ou enfurecido age na ignorância, mas não por ignorância, sendo portanto responsável” (Ética a Nicômaco, III, 1, 1110 b25s; cf. Aristóteles 3, tradução da versão inglesa de W. D. Ross). Aristóteles também afirma que "sucede até que um homem seja punido pela sua própria ignorância quando o julgam responsável por ela, como no caso das penas dobradas para os ébrios; pois o princípio motor está no próprio indivíduo, visto que ele tinha o poder de não se embriagar, e o fato de se haver embriagado foi causa de sua ignorância" (id., III, 5, 1113 b30s). 


\section{Referências Bibliográficas}

1. ALLISON, H. E. "Entre la cosmología y la autonomía: La teoría kantiana de la libertad en la Crítica de la razón pura". In: El idealismo transcendental de Kant: una interpretación y defensa. GRANJA CASTRO, D. (trad.). Barcelona/ México; Anthropos/ Universidad Autónoma Metropolitana - Iztapalpa, 1992.

2. Kant's theory of freedom. New York, Cambridge University Press, 1990.

3. ARISTÓTELES. Ética a Nicômaco. VALLANDRO, L. \& BORNHEIM, G. (trads.). São Paulo, Nova Cultural, 1987.

4. BECK, L. W. A Commentary on Kant's Critique of pratical reason. Chicago, The University of Chicago Press, 1966.

5. BENNETT. J. La 'Crítica de la razón pura', 2, La Dialética. Madrid, Alianza Editorial, 1981.

6. DELBOS, V. La philosophie pratique de Kant. Paris, PUF, 1969.

7. KANT, I. Crítica da razão pura. SANTOS, M. P. dos \& MORUJÃO, A. F. (trads.). Lisboa, Calouste Gulbenkian, 1994.

8. Crítica da razão pura. ROHDEN, V. \& MOOSBURGUER, U. B. (trads.). São Paulo, Abril Cultural, 1980.

9. Kritik der reinen Vernunft. In: Werkausgabe. v. 3/4. WEISCHEDEL, W. (ed.). Frankfurt a. M., Surkamp, 1991.

10. __ “Resposta à pergunta: que é o iluminismo?". In: $A P a z$ perpétua e outros opúsculos. MORÃO, A. (trad.). Lisboa, Edições 70 .

11. Lecciones de ética. RODRIGUEZ ARAMAYO, R. \& ROLDAN PANADERO, C. (trads.). Barcelona. Crítica, 1988. 
12. Fundamentação da metafisica dos costumes. Quintela, P. (trad.). São Paulo, Abril Cultural, 1980.

13. . Crítica da razão prática. MORÃO, A. (trad.). Lisboa, Edições 70, 1986.

14. Kritik der praktischen Vernunft. In: Werkausgabe. v. 7. WEISCHEDEL, W. (ed.). Frankfurt a. M., Surkamp, 1991.

15. . Crítica da faculdade do juízo. ROHDEN, V. \& MARQUES, A. (trad). Rio de Janeiro, Forense, 1993.

16. . Kritik der Urteilskraft. In: Werkausgabe. v. 10. WEISCHEDEL, W. (ed.). Frankfurt a. M., Surkamp, 1991.

17. . A Religião nos limites da simples razão. MORÃO, A. (trad.). Lisboa, Edições 70, 1992.

18. . Die Religion innerhalb der Grenzen der blossen Vernunft. In: Werkausgabe. v. 7. WEISCHEDEL, W. (ed.). Frankfurt a. M., Surkamp, 1991.

19. . La metafisica de las costumbres. CORTINA ORTS, A. \& CONILL SANCHO, J. (trads.). Madri, Tecnos, 1994.

20. . Die Metaphysik der Sitten. In: Werkausgabe. v. 8. WEISCHEDEL, W. (ed.). Frankfurt a. M., Surkamp, 1991.

21. . Anthropologie du point de vue pragmatique. FOUCAULT, M. (trad.) Paris, J. Vrin, 1964.

22. SCHOPENHAUER, A. O mundo como vontade e representação. CORREIA, M. F. S. (trad.). Porto, Rés, s/d.

23. Sobre o fundamento da moral. CACCIOLA, M. L. (trad.). São Paulo, Martins Fontes, 1995.

24. _ Essai sur le libre arbitre. 133a ed. REINHACH, S. (trad.). Paris, Félix Alcan, 1925. 